\title{
Определение следов \\ стабилизаторов химической стойкости бездымных порохов методом тандемной газовой хромато-масс-спектрометрии
}

\author{
А. В. Ладонин, Ю.Б.Тузков, \\ ЭКЦ МВД России, Москва \\ chemmaster@mail.ru
}

Удк $543.51 ; 543.544 .3$

\begin{abstract}
Предложен способ высокочувствительного одновременного определения стабилизаторов химической стойкости бездымных порохов - дифениламина, централита I (N,N'-диэтил-N,N'-дифенилмочевины) и централита II (N,N'-диметил$\mathrm{N}, \mathrm{N}$ '-дифенилмочевины) методом газовой хроматографии - тандемной массспектрометрии. Оптимизированы параметры детектирования аналитов в режиме мониторинга выбранных реакций, подобраны условия их эффективного разделения на неполярной колонке TG-5MS. Установлены пределы детектирования, разработан метод количественного анализа с использованием внутреннего стандарта.
\end{abstract}

\section{ВВЕДЕНИЕ}

Анализ следов продуктов выстрела - один из важнейших этапов в ряде судебных экспертиз. Продукты выстрела делятся на неорганические и органические. Неорганические представляют собой остатки от сгорания ударно-воспламенительного состава, а также компоненты, образующиеся при частичном разрушении капсюля, механического износа гильзы и снаряда в процессе прохождения снаряда по стволу оружия и в результате воздействия газообразных продуктов горения пороха и капсюльного состава. Органические компоненты относятся к продуктам сгорания бездымных порохов, которыми снаряжаются патроны к огнестрельному оружию. Бездымные пороха делятся на одноосновные и двухосновные. В составе одноосновных содержатся нитраты целлюлозы, пластификаторы (фталаты), флегматизаторы (камфора), стабилизаторы химической стойкости (дифениламин), пламегасители и различные технологические добавки. В состав двухосновных порохов, кроме перечисленных компонентов входят жидкие нитроэфиры (нитроглицерин, этиленгликольдинитрат и др.), причем в качестве стабилизаторов химической стойкости используют диалкилдифенилмочевины, также известные, как централиты [1-3]. Наиболее часто встречаются централит I (N,N'-диэтил$\mathrm{N}, \mathrm{N}$ '-дифенилмочевина) и централит II (N,N'-диметил-N,N'дифенилмочевина).
Отметим, что кроме использования в качестве стабилизатора химической стойкости порохов дифениламин довольно широко применяется в различных областях промышленного органического синтеза и ограниченно - в быту (ингибиторы коррозии, присадки в смазочных материалах и т.д.). При этом данных об использовании централитов где-либо, кроме как в качестве стабилизаторов химической стойкости порохов, мы не обнаружили [4].

Для анализа органических следов продуктов выстрела (далее - ОСПВ), а именно стабилизаторов химической стойкости порохов, применяется газовая хроматография с различными типами детекторов, в том числе массспектрометрическим детектированием (ГХ-МС). Пределы детектирования методом ГХ-МС дифениламина и централитов составляют порядка 1 нг / мкл (1·103 нг / мл) [5]. В ряде случаев, для снижения предела обнаружения дифениламина и улучшения формы хроматографического пика, проводят предварительную дериватизацию - получение трифторацетильного производного дифениламина [6]. Повышение чувствительности и селективности анализа таких объектов, как смывы с рук и одежды проверяемых лиц, оружия и пораженных объектов, возможно за счет применения тандемной масс-спектрометрии. В ряде работ описан метод высокоэффективной (ВэжХ) или ультра 
высокоэффективной (УВэЖХ) жидкостной хроматографии с тандемным масс-спектрометрическим детектированием (MC/MC) $[4,7,8]$ для анализа ОСпВ, причем пределы детектирования могут достигать 0,29 нмоль/л (0,05 нг/мл) для дифениламина и 0,07 нмоль/л (порядка 0,02 нг/мл) для централитов [4]. Однако, в литературе практически отсутствуют данные по определению Оспв методом газовой хроматографии с тандемным масс-спектрометрическим детектированием (ГХ-МС/ МС).

Цель настоящего исследования разработка метода высокочувствительного одновременного определения стабилизаторов химической стойкости бездымных порохов - дифениламина, централита I (N,N'-диэтилN,N'-дифенилмочевины) и централита II (N,N'-диметил-N,N'-дифенилмочевины) методом ГX-MC/MC.

\section{ЭКСПЕРИМЕНТАЛЬНАЯ ЧАСТЬ}

Оборудование. Анализ проводили на хромато-массспектрометрическом (ХМС) комплексе, состоящем из газового хроматографа Trace 1310 (Thermo Scientific) и тандемного масс-спектрометрического детектора TSQ-8000 (Thermo Scientific) с тройным квадруполем. Разделение осуществляли на кварцевой капиллярной колонке TG-5MS (20 м × 0,25 мм, толщина пленки фазы - 0,25 мкм). Использовали следующие параметры работы ХМС-комплекса: газ-носитель - гелий высокой чистоты марки «5.5» (99,9995\%), постоянный поток 1 мл / мин; температура инжектора - $280{ }^{\circ} \mathrm{C}$, температура устройства сопряжения (интерфейса детектора) - $250{ }^{\circ} \mathrm{C}$. Режим ионизации - электронный удар с энергией 70 эВ, детектирование проводили в комбинированном режиме по мониторингу выбранных реакций и по полному ионному току. В качестве газа в ячейке соударений использовали аргон. Для управления ХМС-комплексом, сбора и обработки данных применяли программное обеспечение Xcalibur (Thermo Scientific).

Спектры ядерно-магнитного резонанса 'H анализируемых соединений записывали на ЯМР-спектрометре Bruker Ascend 500 с рабочей частотой 500 МГц.

ИК-спектры анализируемых соединений записывали на ИК-Фурье-спектрометре Nicolet iS50 Thermo Fisher Scientific в диапазоне волновых чисел 4000-400 $\mathrm{cm}^{-1}$ с разрешением $4 \mathrm{~cm}^{-1}$. Для анализа использовали встроенный модуль однократного нарушенного полного внутреннего отражения (HПBO) модели iS50 ATR с кристаллом из монолитного кристаллического углерода.
Определяемые соединения. Для исследования выбрали аналиты N,N'-диэтил-N,N'-дифенилмочевина (централит I), $\mathrm{N}, \mathrm{N}$ '-диметил-N, N'-дифенилмочевина (централит II) и дифениламин (рис. 1). Снижение предела обнаружения и улучшения формы хроматографического пика достигали предварительной подготовкой образцов для анализа. Для этого путем взаимодействия с трифторуксусным ангидридом получали трифторацетильное производное дифениламина (ДФТФА), а затем проводили перекристаллизацию полученного продукта из изопропанола. В качестве внутреннего стандарта для количественного анализа использовали гексахлорбензол (ГХБ). Чистоту анализируемых соединений подтверждали данными ИК-спектрометрии, а также спектрометрии ЯМР.

Приготовление градуировочных растворов. Стандартные растворы всех исследуемых соединений с концентрацией 40 мкг / мл готовили в хлористом метилене. Рабочие растворы готовили путем разбавления стандартного раствора в диапазоне концентраций 40 мкг / мл - 0,01 нг/ мл и хранили при $4^{\circ} \mathrm{C}$ не более суток.

\section{РЕЗУЛЬТАТЫ И ОБСУЖДЕНИЕ}

\section{Оптимизация параметров}

\section{масс-спектрометрического детектирования}

Стандартные образцы концентрацией 40 мкг / мл вводили в хроматографическую колонку, затем проводили массспектрометрическое детектирование в режиме сканирования по полному ионному току на первом квадруполе и получали спектры электронной ионизации для каждого компонента (табл. 1). После детектирования в режиме мониторинга заданных реакций выбирали ионы-предшественники, а в качестве ионов-продуктов - фрагментные 
Таблица 1. Масс-спектры электронной ионизации исследуемых соединений

\begin{tabular}{|l|c|c|c|c|c|c|c|c|}
\hline Соединение & $\begin{array}{c}\text { Молекулярная } \\
\text { масса, Да }\end{array}$ & \multicolumn{5}{|c|}{ m / z основных ионов, Да (относительная интенсивность) } \\
\hline ДФТФА & 265 & $172(999)$ & $265(960)$ & $167(755)$ & $77(733)$ & $168(731)$ & $51(565)$ \\
\hline ГХБ & $289(213)$ \\
\hline Централит II & 240 & $284(999)$ & $286(794)$ & $282(533)$ & $142(446)$ & $288(343)$ & $107(286)$ & $249(285)$ \\
\hline Централит I & 268 & $134(999)$ & $240(451)$ & $106(327)$ & $77(302)$ & $135(90)$ & $241(77)$ \\
\hline
\end{tabular}

ионы, дающие наиболее интенсивные сигналы. Для централита I взяли два иона-продукта (m/ z 120 и 148) и сравнили интенсивности хроматографических пиков, соответствующих выбранным ионным переходам в зависимости от приложенной энергии соударений. Зависимости площадей пиков от энергии соударений (по данным трех параллельных определений) приведены на рис. 2.

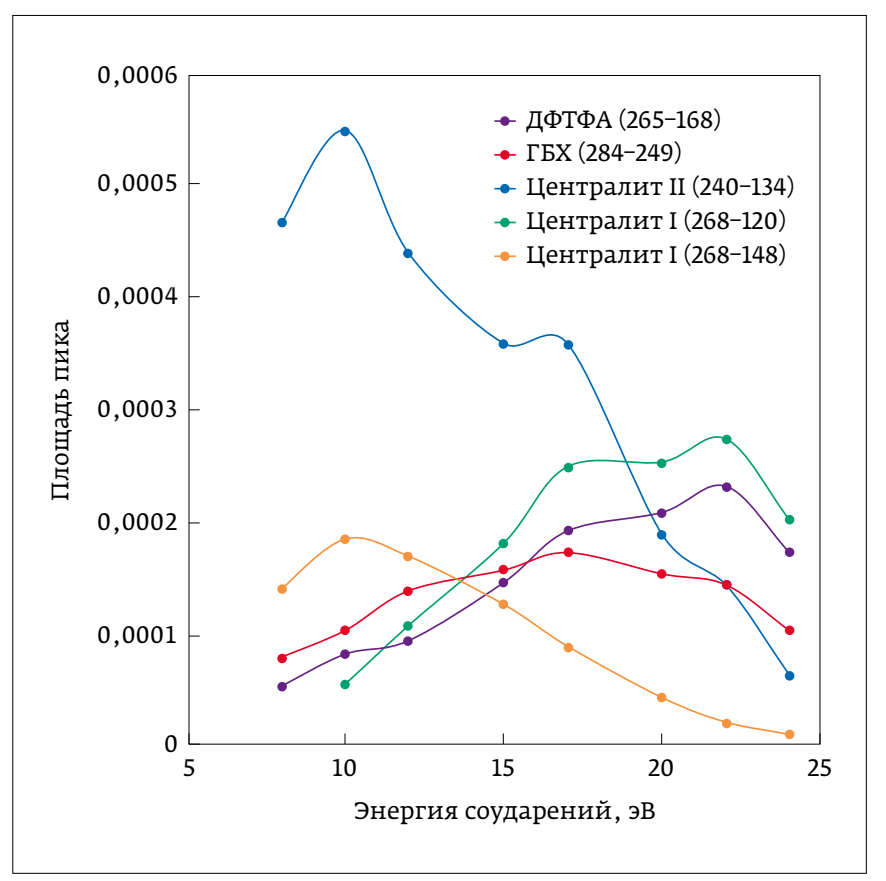

Puc. 2. Оптимизация энергии соударений
Путем записи хроматограмм модельной смеси аналитов в режиме мониторинга заданных реакций проводили тонкую настройку энергии соударения с шагом 2-3 эВ. Полученные результаты оптимизации масс-спектрометрического детектирования представлены в табл. 2.

\section{Подбор условий хроматографического разделения} На первом этапе выбирали растворитель образца: метанол, изопропанол, ацетон, хлористый метилен или хлороформ. Критерии отбора включали: способность к растворению представляющих интерес компонентов пробы, полнота извлечения их из матрицы, доступность соответствующего высокочистого растворителя, по возможности минимальная токсичность, а также инертность к компонентам пробы. По всем параметрам лучше всех для приготовления растворов подошел хлористый метилен.

Кратность деления потока при вводе пробы в хроматографическую колонку подбирается исходя из концентрации аналитов. Для достижения минимальных пределов обнаружения, при концентрации целевых компонентов ниже 200 нг/мл, пробы вводили в режиме без деления потока.

Учитывая достаточную термическую стабильность исследуемых соединений, температуру узла ввода пробы устанавливали равной $280^{\circ} \mathrm{C}$. Начальная температура термостата колонки составляла $70{ }^{\circ} \mathrm{C}$ для устранения влияния растворителя на разделение компонентов. Скорость изменения температуры -10 $\mathrm{C}$ мин с изотермической задержкой 2 мин позволила полностью разделить аналиты. Для очистки хроматографической колонки после проведения анализа ее выдерживали при конечной температуре в течение 10 мин.

Таблица 2. Параметры масс-спектрометрического детектирования исследуемых соединений в режиме мониторинга заданных реакций

\begin{tabular}{|c|c|c|c|c|}
\hline Соединение & $\begin{array}{c}\text { Ион-предшественник, } \\
\text { m/z }\end{array}$ & $\begin{array}{c}\text { Ион-продукт, } \\
\mathrm{m} / \mathrm{z}\end{array}$ & $\begin{array}{c}\text { Энергия соударений, } \\
\text { эВ }\end{array}$ & Отщепляемый фрагмент \\
\hline ДФТФА & 265 & 168 & 22 & $-\mathrm{C}_{2} \mathrm{~F}_{3} \mathrm{O}$ \\
\hline ГХБ & 284 & 249 & 17 & $-\mathrm{Cl}$ \\
\hline Централит II & 240 & 134 & 10 & $-\mathrm{C}_{9} \mathrm{H}_{10} \mathrm{NO}$ \\
\hline Централит I & 268 & 120 & 22 & $-\mathrm{C}_{7} \mathrm{H}_{8} \mathrm{~N}$ \\
\hline
\end{tabular}




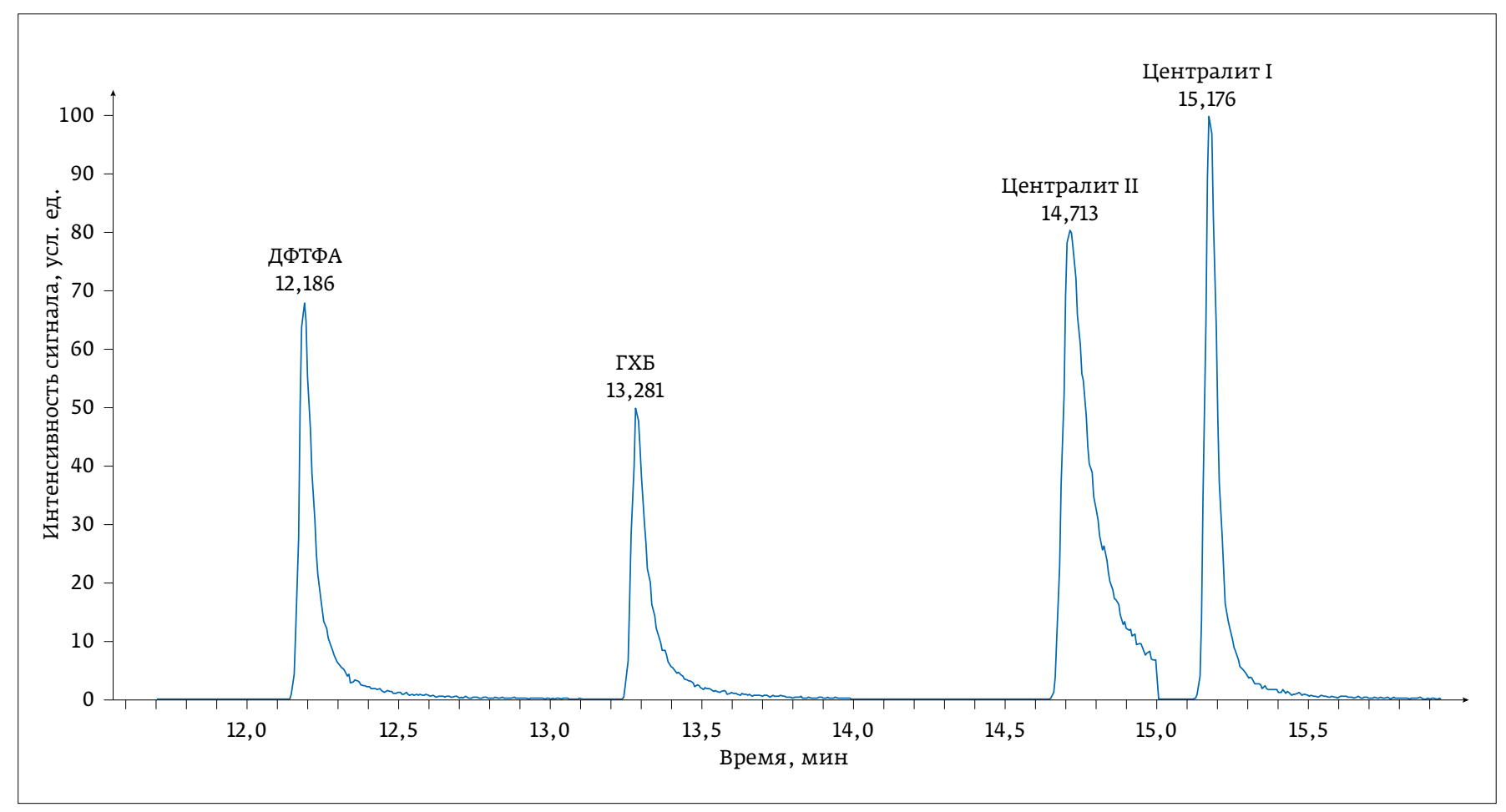

Puc. 3. Фрагмент хроматограммы модельной смеси исследуемых соединений (40 нг/ мл) в режиме мониторинга заданных реакций (SRM)

\section{Количественный анализ}

Количественный анализ проводили по методу внутреннего стандарта, основное достоинство которого - минимальная погрешность, вызванная случайными изменениями параметров хроматографического опыта - температуры, скорости газа-носителя и режима работы детектора. Возможные отклонения от заданных условий равным образом влияют на количественные параметры хроматографических пиков как стандартного, так и анализируемого соединений. Отпадает необходимость дозирования строго заданных количеств пробы и соблюдения постоянства всех переменных параметров хроматографирования $[9,10]$. В качестве внутреннего стандарта выбрали гексахлорбензол, так как он доступен, имеет подходящие хроматографические характеристики, инертен к определяемым соединениям, растворителям и компонентам матрицы, а также отсутствует в объектах исследования.

Изучение стандартных образцов показало, что градуировочные зависимости площадей хроматографических пиков от концентрации линейны для всех компонентов

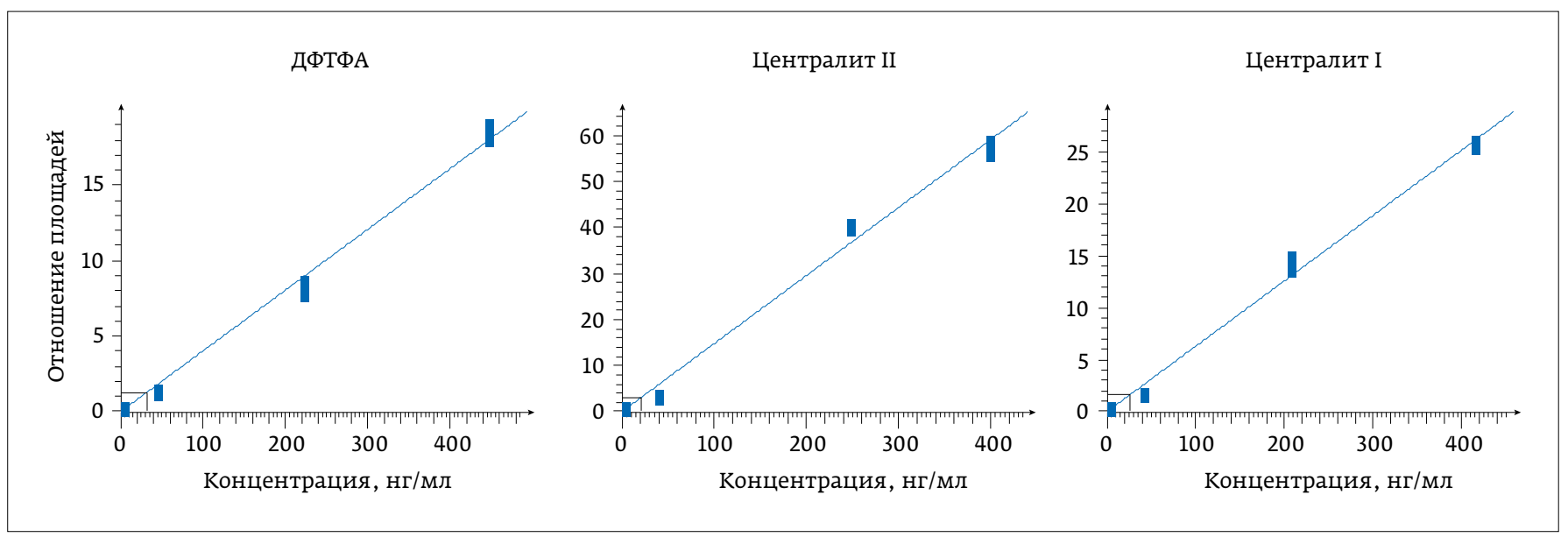

Puс. 4. Градуировочные зависимости отнощения площадей хроматографических пиков определяемых соединений к площади пика внутреннего стандарта от концентрации 
Таблица 3. Метрологические характеристики определения целевых соединений методом ГХ-МС/МС

\begin{tabular}{|c|c|c|c|c|c|}
\hline Соединение & $\begin{array}{l}\text { Время } \\
\text { удерживания, } \\
\text { мин }\end{array}$ & $\begin{array}{c}\text { Предел } \\
\text { обнаружения, } \\
\text { нг/мл }\end{array}$ & $\begin{array}{c}\text { Минимальное } \\
\text { определяемое содержание, } \\
\text { нг/ мл }\end{array}$ & $a$ & $\mathbf{R}^{2}$ \\
\hline ДФТФА & 12,2 & \multirow{3}{*}{0,1} & 4,5 & 0,040 & 0,993 \\
\hline Централит II & 14,7 & & 4,0 & 0,148 & 0,990 \\
\hline Централит I & 15,2 & & 4,2 & 0,063 & 0,993 \\
\hline
\end{tabular}

в диапазоне от 4 до 400 нг / мл и описываются уравнением вида $y=a x$ с коэффициентом корреляции $\mathrm{R}^{2}$ более 0,99 (рис. 4). Рассчитаны пределы обнаружения и минимальное определяемое содержание для изучаемых соединений (табл. 3).

Пределы обнаружения определяемых веществ также устанавливали в режимах сканирования по полному ионному току (TIC) и поиску избранных ионов (SIM). В диапазоне сканирования 42-550 Да в режиме ТІС пределы обнаружения определяемых веществ составляют порядка 40 нг / мл (рис. 5), в режиме SIM (поиск осуществлялся по молекулярным ионам) - порядка 4 нг / мл (рис. 6).

Полученные результаты показывают, что применение техники тандемной хромато-масс-спектрометрии позволяет не только повысить селективность анализа следов стабилизаторов химической стойкости бездымных порохов, но и радикально увеличить чувствительность по сравнению с методом ГХ-МС без дополнительного концентрирования образцов (рис. 7). Например, достигнутые пределы обнаружения ДФТФА и централитов в режиме SRM на один-два порядка ниже, чем в режимах SIM и TIC.

\section{ЗАКЛЮЧЕНИЕ}

С помощью оборудования ГХ-МС/MС можно существенно повысить чувствительность и селективность определения следов стабилизаторов химической стойкости бездымных порохов в составе таких объектов, как смывы с рук и одежды проверяемых лиц, оружия и пораженных объектов. Достигнутые пределы обнаружения на уровне 0,1 нг / мл, а также широкий динамический диапазон, охватывающий более трех порядков, открывают новые возможности следового анализа при проведении судебных экспертиз.

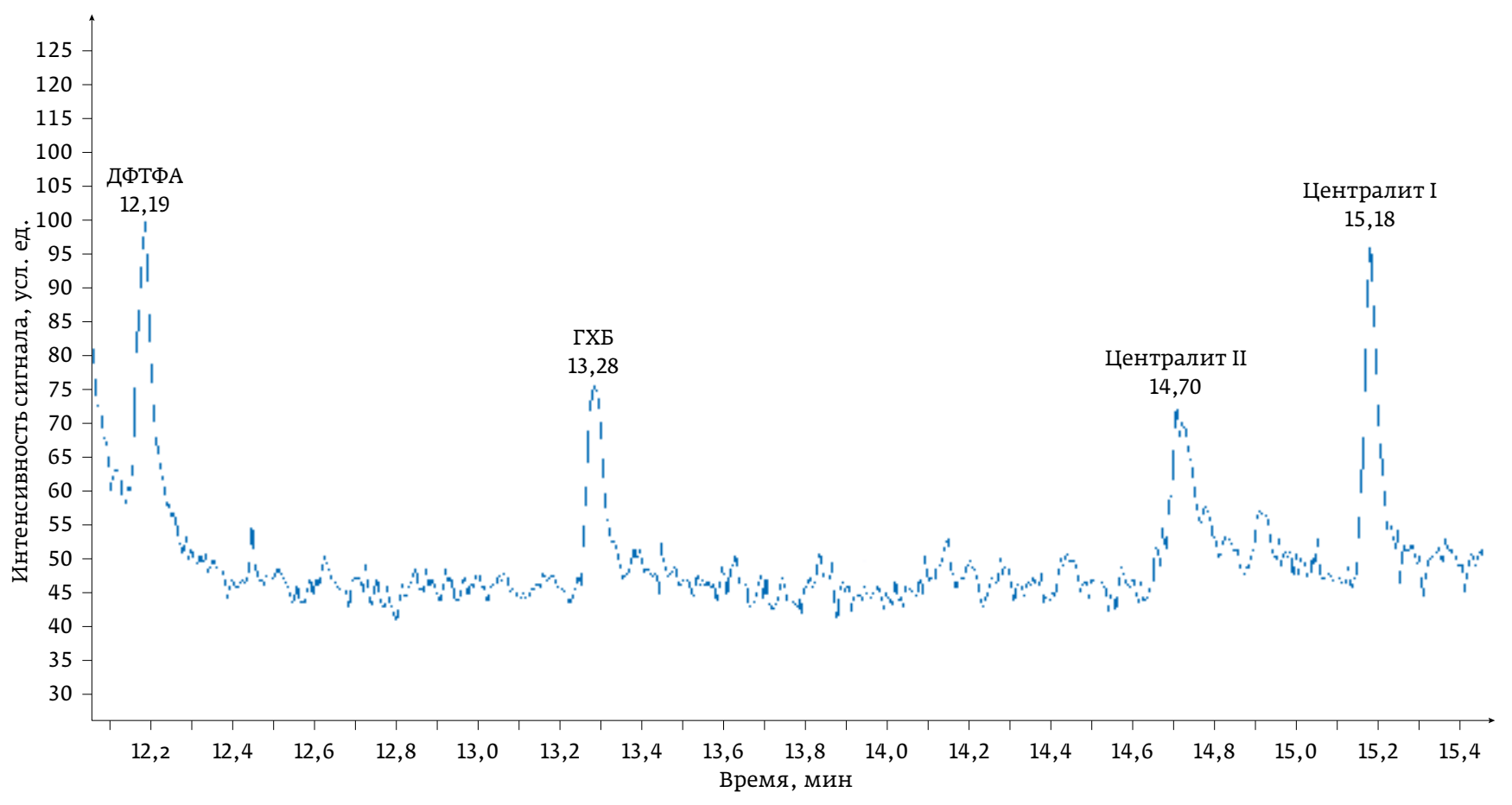




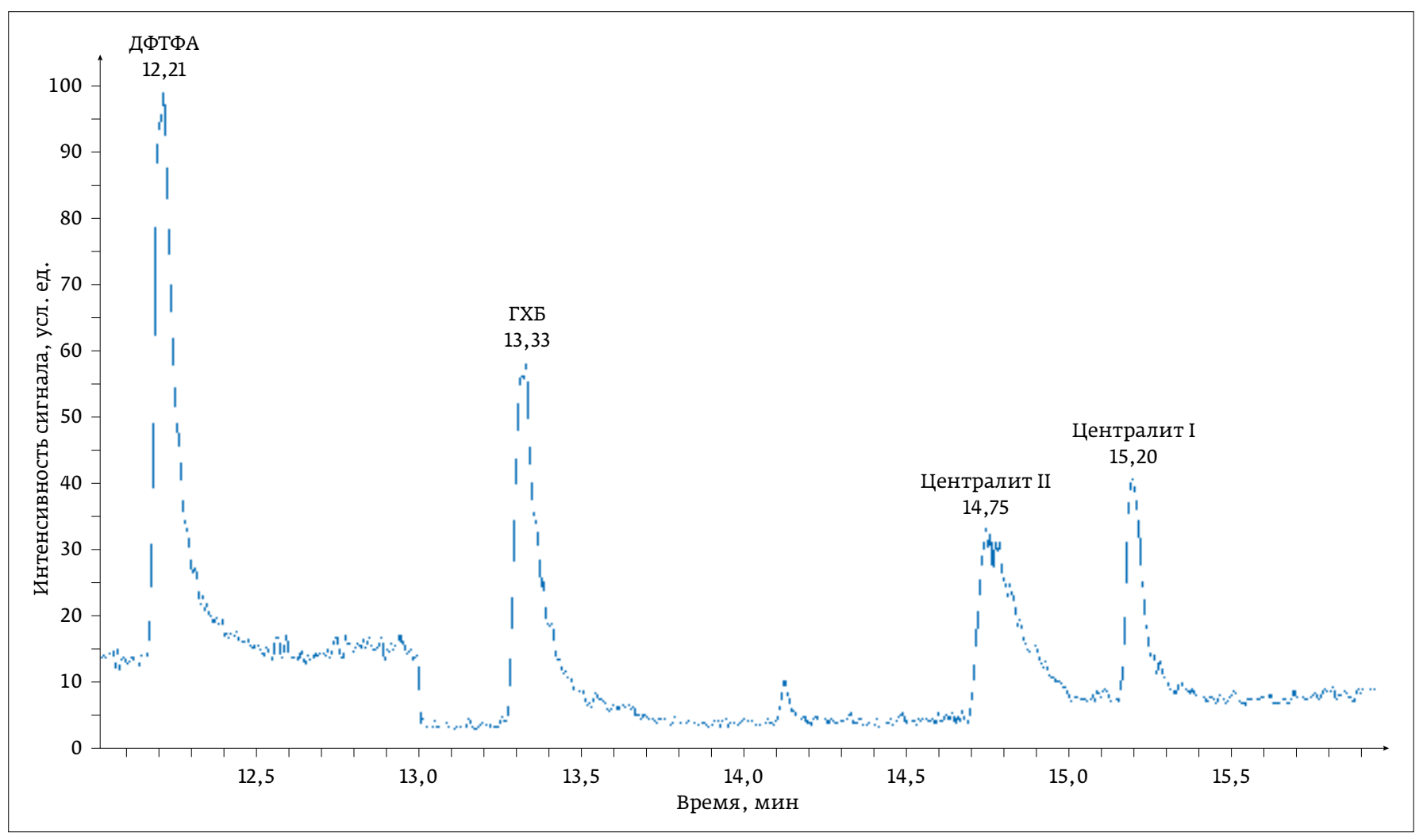

Puc. 6. Фрагмент хроматограммы модельной смеси исследуемых соединений (4 нг / мл) в режиме SIM

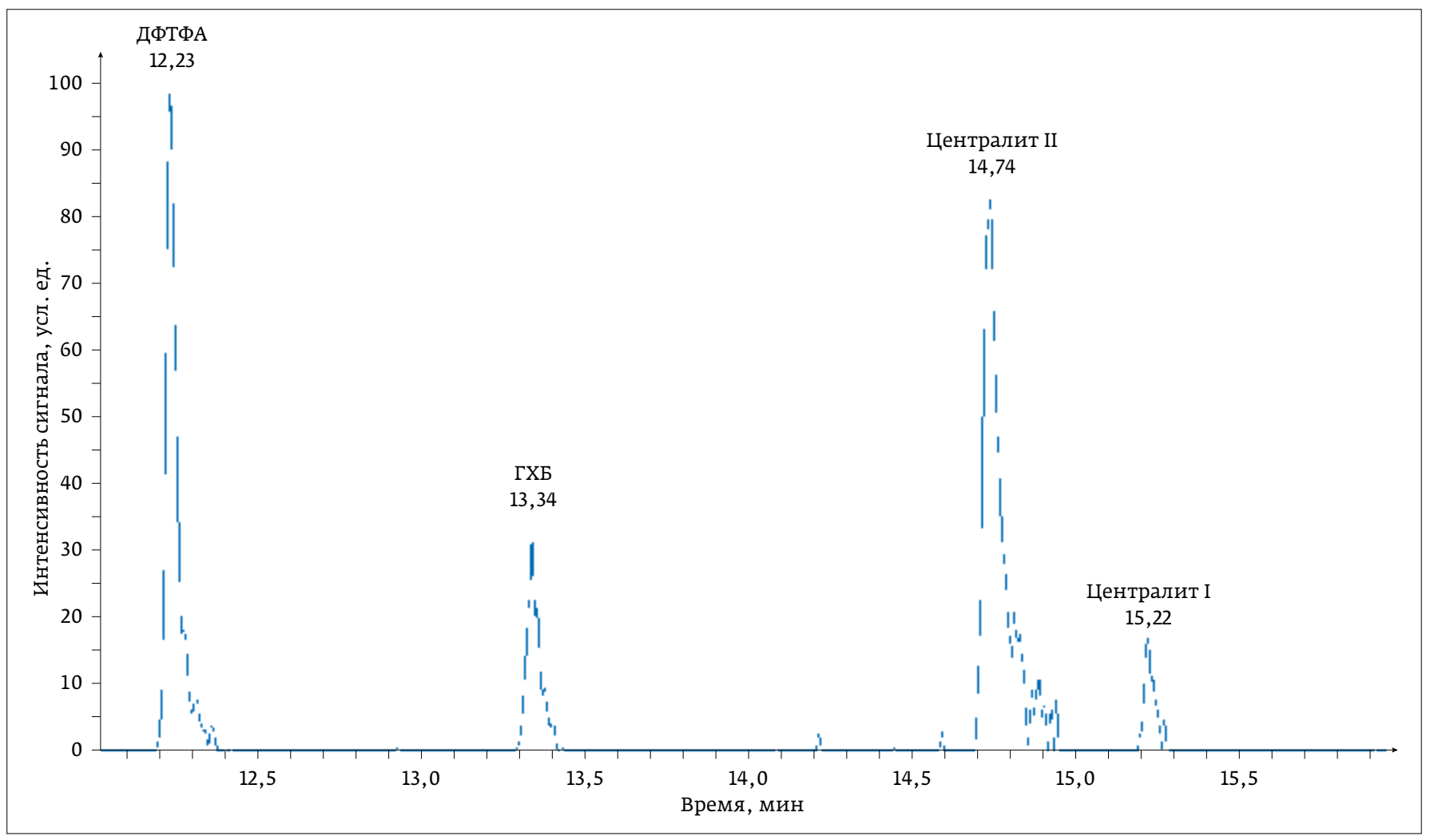

Puc. 7. Фрагмент хроматограммы модельной смеси исследуемых соединений $(0,1$ нг / мл) в режиме SRM 


\section{ЛИТЕРАТУРА}

1. Dalby O., Butler D., Birkett, J.W. Analysis of Gunshot Residue and Associated Materials - A Review // J Forensic Sci. 2010. V. 55. No 4 PP. 924-943.

2. Фиошина М.А., Русин Д.Л. Основы химии и технологии порохов и твердых ракетных топлив: Учеб. пособие / РХТУ им. Д. И. Менделеева. M., 2001.

3. Urbanski T. Smokeless powder // Chemistry and Technology of Explosives: V. 4. Warszawa: Регgamon Ргеss., 1984.

4. Laza D., Nys B., De Kinder J., Kirsch-De Mesmaeker A., Moucheron C Development of a Quantitative LC-MSMS Method for the Analysis of Common Propellant Powder Stabilizers in Gunshot Residue // J Forensic Sci, July 2007. V. 52. No. 4. PP. 842-850.

5. Speers SJ, Doolan K, McQuillan J, Wallace JS. Evaluation of improved methods for the recovery and detection of organic and inorganic cartridge discharge residues // J. Chromatogr A 1994;674(1-2): pp.319-327.

6. Ануфриев М.В., Бачурин Л.В., Мокроусов А.А. и др. Выявление продуктов выстрела на руках и одежде проверяемых лиц с целью установления факта производства выстрела: Методические рекомендации. - М.: ГУЭКЦ МВД России, 2001.

7. Thomas J. L., Lincoln D., McCord B. R. Separation and Detection of Smokeless Powder Additives by Ultra Performance Liquid Chromatography with Tandem Mass Spectrometry (UPLC/MS/MS) // J Forensic Sci. 2013. V. 58. No 3. PP. 609-615.

8. Zhao M.; Zhang S.; Yang C.; Xu Y.; Wen Y.; Sun L. and Zhang X. Desorption Electrospray Tandem MS (DESI-MSMS) Analysis of Methyl Centralite and Ethyl Centralite as Gunshot Residues on Skin and Other Surfaces // J Forensic Sci. 2008. V. 53. No 4. PP. 807-811.

9. Harris D.C. Quantitative Chemical Analysis. Seventh edition W. H. Freeman and Company, New York, 2007.

10. Количественный газохроматографический анализ. Методические указания к выполнению лабораторной работы по курсу физико-химических методов анализа. / Сост. Апраксин В. Ф.- СПб.: СПХФА, 1999.

\section{REFERENCES}

1. Dalby O., Butler D., Birkett, J.W. Analysis of Gunshot Residue and Associated Materials - A Review // J Forensic Sci. 2010. V. 55. No 4. PP.924-943.

2. Fioshina M.A., Rusin D. L. Fundamentals of chemistry and technology of powders and solid rocket fuels: Tutorial. - Moscow, D. Mendeleev University of Chemical Technology of Russia Publ., 2001

3. Urbanski T. Smokeless powder. Chemistry and Technology of Explosives: V. 4. Warszawa: Регgamon Рress, 1984

4. Laza D., Nys B., De Kinder J., Kirsch-De Mesmaeker A., Moucheron C. Development of a Quantitative LC-MSMS Method for the Analysis of Common Propellant Powder Stabilizers in Gunshot Residue // J Forensic Sci. 2007. No 4 PP. 842-850.

5. Speers S.J., Doolan K., McQuillan J., Wallace J. S. Evaluation of Improved Methods for the Recovery and Detection of Organic and Inorganic Cartridge Discharge Residues. J Chromatogr A 1994;674(1-2): pp.319-327.

6. Anufriev M.V., Bachurin L.V., Mokrousov A.A. and others. Identification of Products of a Shot on Hands and Clothes of the Checked Persons for the Purpose of Establishment of the Fact of Production of a Shot: Methodical Recommendations.Moscow, Forensic Science Center of the MIA of Russia Publ., 2001.

7. Thomas J. L., Lincoln D., McCord B. R. Separation and Detection of Smokeless Powder Additives by Ultra Performance Liquid Chromatography with Tandem Mass Spectrometry (UPLC/MS/MS) // J Forensic Sci. 2013. V. 58. No 3. PP. 609-615.

8. Zhao M.; Zhang S.; Yang C.; Xu Y.; Wen Y.; Sun L. and Zhang X. Desorption Electrospray Tandem MS (DESI-MSMS) Analysis of Methyl Centralite and Ethyl Centralite as Gunshot Residues on Skin and Other Surfaces // J Forensic Sci. 2008. V. 53. No 4. PP. 807-811.

9. Harris D.C. Quantitative Chemical Analysis. Seventh edition. W. H. Freeman and Company, New York, 2007

10. Ouantitative Gas Chromatographic Analysis. Guidelines for Laboratory Work on the Course of Physical and Chemical Methods of Analysis. Compiled By Apraksin V. F. - Saint-Petersburg, Saint Petersburg State Chemical Pharmaceutical Academy Publ., 1999.

\section{МИКРОПЛАСТИК СТАЛ ЧАСТЬЮ ГЛУБОКОВОДНЫХ ЭКОСИСТЕМ}

Загрязнение воды на Земле микропластиком и его вредное воздействие на морских животных общепризнанно. Однако глубина проблемы стала ясна лишь в январе этого года. Исследуя различия между видами амфиподов (бокоплавов) в глубочайших морских впадинах Земли, ученые обнаружили в их телах непереваренный микропластик.

На Земле производится десять тонн пластика ежесекундно, 5-14 миллионов тон пластика оказывается в океанах каждый год. Этот мусор выбрасывается на пляжи, плавает на поверхности в виде мельчайших частиц, попадает в тела морских птиц и животных, или опускается на дно.

Морские биологи из Англии изучали видовые различия амфиподов в шести океанических углублениях Земли, включая Марианскую впадину. Пробы отбирали на глубине от 7000 до 10890 м. Тела $72 \%$ выловленных животных содержали по крайней мере одну частицу пластика, а в среднем, на одну особь приходилось от одного до восьми пластиковых фрагментов, причем с глубиной их число возрастало. Все афамиподы из Марианской впадины имели в желудке непереваренный пластик. Некоторые частицы были относительно большими: кусочек пластика длиной в миллиметр в теле животного не больше полусантиметра по объему равносилен метровой веревке в теле человека. Образцы пластика проанализировали методом ИК-фурье-спектроскопии и подтвердили их синтетическую природу. В тела амфиподов попали: нейлон, полиэтилен, полиамид, поливинилхлорид, район, лиоцелл. Скапливаясь в организме животных, пластик может

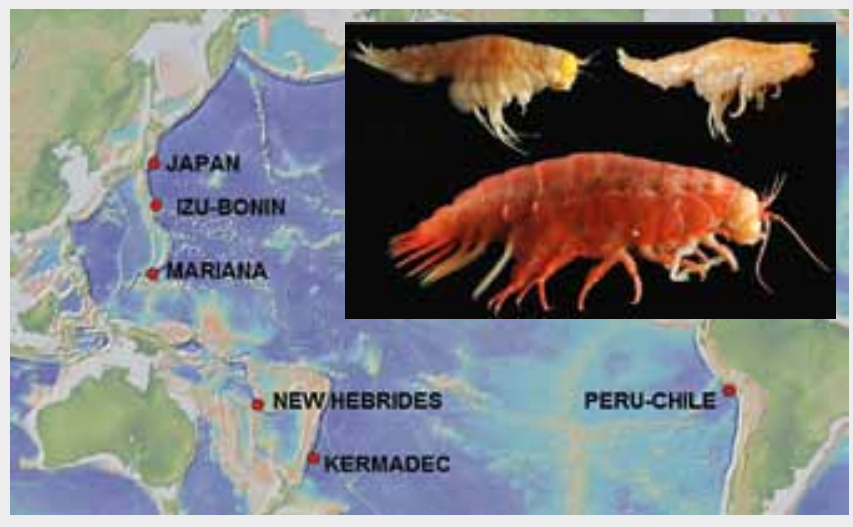

повреждать их пищеварительную систему, а также концентрировать на своей поверхности различные токсины, например, полихлорфенилы.

Амфиподы, родственники крабов, работают своеобразными санитарами морских глубин. Они прокачивают через свои тела воду в поисках еды и сами являются пищей (и источником микропластика) для креветок, рыб, морских животных и, в конечном итоге, для человека.

Исследование показало, что антропогенный мусор является биодоступным для организмов в самых глубоких местах Земли.

R. Soc. Open Sci., 2019. http://dx.doi.org/10.1098/rsos.180667 


\section{Pентеновские анализаторы для измерения массовой доли серы в нефртепродуктах}

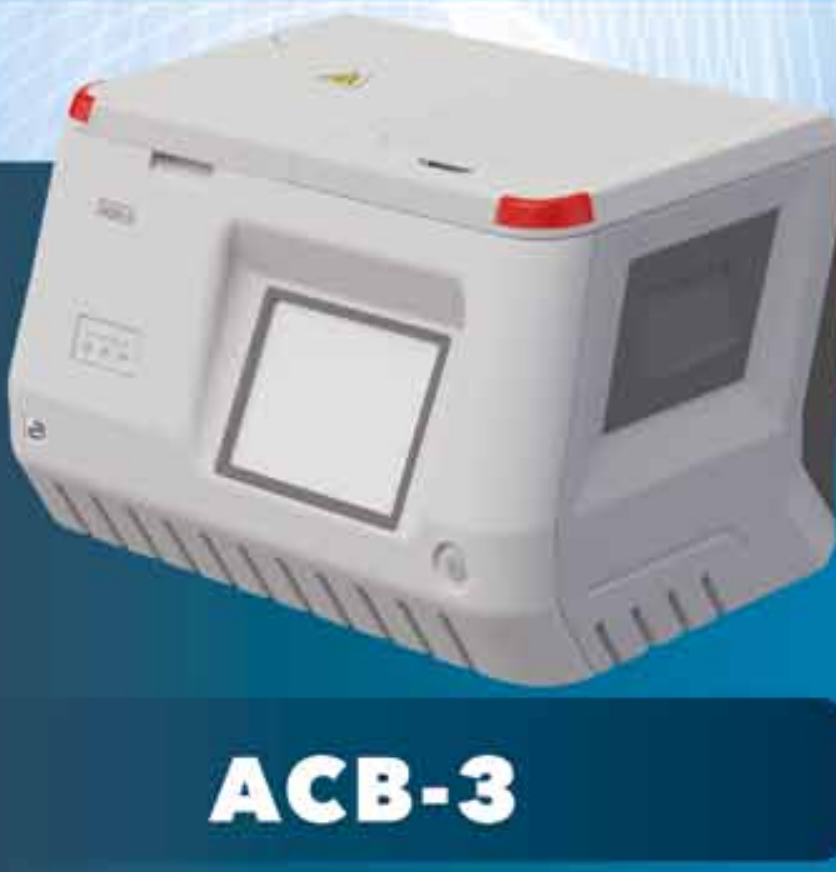

Анализатор серы рентгенофлуоресцентный волнодисперсионный

$\checkmark$ Диапазон измеряемых концентраций серы - от $3 \mathrm{mr} / \mathrm{kr}$

$\checkmark$ Соответствие ГОСТ Р 52660, ГОСТ ISO 20884, ГOCT 53203, ASTM D6334, ASTM D6222

$\checkmark$ Арбитражный анализ топлив экологических классов К2, К3, К4, К5

$\checkmark$ Диск пробоподачи на 9 образцов

$\checkmark$ Доступны 2 режима эксплуатации: вакуум или гелиевый контур

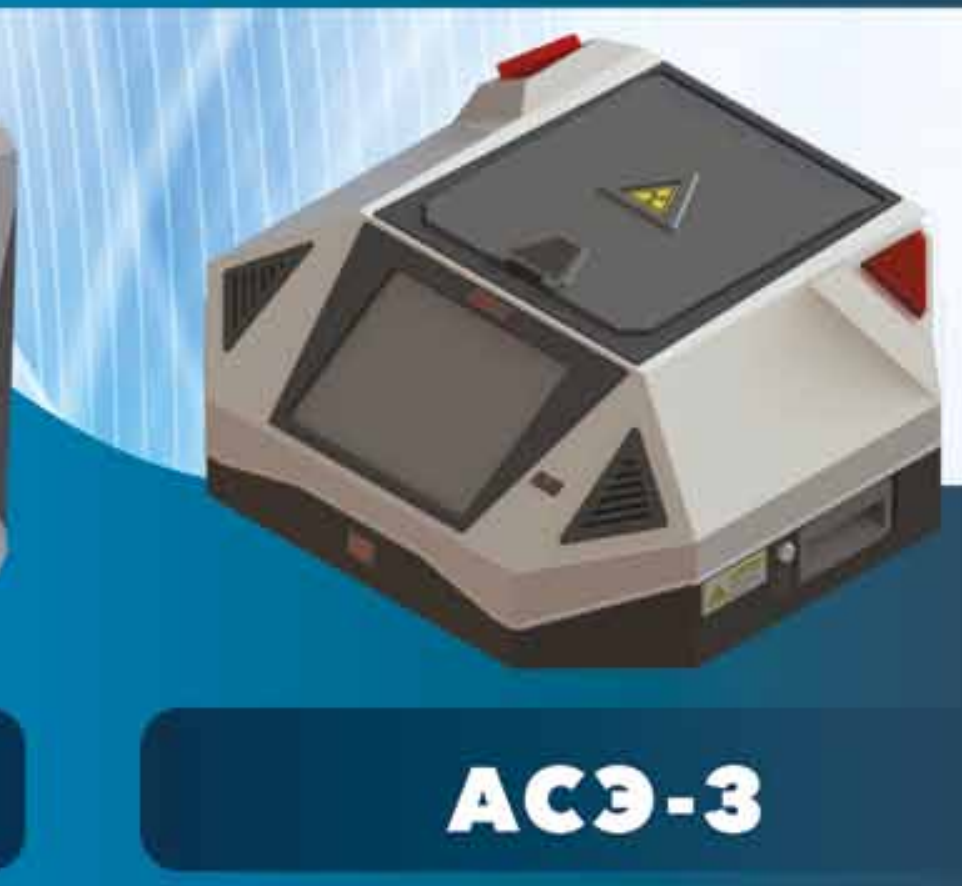

\section{Анализатор серы рентгенофлуоресцентный энергодисперсионный}

$\checkmark$ Диапазон измеряемых концентраций серы - от 5 мг/кг

$\checkmark$ Соответствие ГОСТ Р 51947, ГОСТ ISO 20847, ГOCT 32139, ASTM D4294

$\checkmark$ Арбитражный анализ топлив экологического класса К2

$\checkmark$ Анализ топлив экологических классов К3, К4

$\checkmark$ Диск пробоподачи на 4 образца

$\checkmark$ Возможно подключение к ПК и LIMS

$\checkmark$ Простота и надёжность в эксплуатации

$\checkmark$ Сенсорный дисплей 